\title{
MULTI RESPONSE OPTIMIZATION OF TURNING PROCESS PARAMETERS OF AL-2MG/BLAST FURNACE SLAG REINFORCED COMPOSITES USING THE TAGUCHI APPROACH
}

\author{
J LEELA KRISHNA ${ }^{1} \&$ KOLLA SRINIVAS ${ }^{2}$ \\ ${ }^{I}$ Research scholar, Department of Mechanical Engineering, Acharya Nagarjuna University, Guntur \\ ${ }^{2}$ Professor, Department of Mechanical Engineering, RVR JC College of Engineering, Guntur
}

\section{ABSTRACT}

The present work is focused on the turning process parameters of Al-2Mg alloy reinforced with blast furnace slag particulates. Blast furnace emerges as the significant waste material during the production of pig iron by decrease the iron mineral in the Blast furnace process. Traditional practices such as manufacturing decisions, expert data, and customer requirements result in local solutions i.e., higher quality for one production while sacrificing with the rest. The ENTROPY strategy cripples the previously mentioned restrictions of customary practices and decides weight parts dependent on exploratory information for each yield. The two methodologies utilized for multi-target improvement are Gray relation Analysis (GRA), and Data Envelopment Analysis based Ranking (DEAR). The system of GRA permits the difficult solver to allocate weight divisions for each yield. Recall that the exactness is of the arrangement contrast with the parts of weight distributed to each yield. The total (composite estimations everything being equal) values determined by the technique ENTROPY-GRA and DEAR were utilized to decide ideal degrees of factor and their commitments.

KEYWORDS: Turning, Optimization, ENTROPY, GRA, DEAR

Received: Jun 08, 2020; Accepted: Jun 28, 2020; Published: Sep 10, 2020; Paper Id.: IJMPERDJUN20201147

\section{INTRODUCTION}

Turning operation is a standard machining operation in which rotational parts are being produced by removing material, thereby obtaining the reduced size of the required diameter. The turning operation can be performed generally in the lathe machine with the use of a single-point cutting tool. For turning the workpiece in the lathe, it is required to fix the cutting tool in the fixture, and the workpiece made to be rotated continuously. In various industries, the turning is used mostly in a machining operation to produce the required shape of different components [1-2]. According to the extensive research conducted in the MMC cutting process by the researchers around the globe, it has been found that the main aspects affecting MMC turning operation predominantly depends on the type of material being used [3-4].

Usually, according to the guidelines set by standard handbooks, the experience of operators, and the knowledge, the machining parameters are selected. However, if the chosen machining parameters are not optimum, they may eventually increase product cost [5]. By choosing the best machining parameters, one can achieve high machining performance [6]. During the process of choosing the best combination of best machining parameters, the researcher makes use of the optimization techniques [7]. Novel materials are manufactured to meet specific industry-based requirements in the manufacturing arena. However, it may not be feasible to make use of it directly. So, an experimental study is required here [8]. The MMCs find applications in areas like aircraft components, 
automobile, marine, structural equipment's, etc., Mondolfo et al., [9] developed an MMC's by varying the weight percentage of reinforcements in various wt. Percentages and conducted the mechanical and microstructural analysis. The present examination is centered around turning execution of A7075/ZrO2 AMMC as far as Ra and MRR under dry machining condition with uncoated carbide tipped inserts. When turning MMCs with SS tools, the cutting edge becomes dull immediately, giving short tool life, and hence cutting tools like CBN and PCD are widely used along with carbide tipped tools. Carbide tipped tools are useful in producing better surface quality.Lin et al. [10] to optimize turning operations with different execution attributes, the Taguchi technique and the GRA were utilized. The feed rate of the machine is found to affect the life of the tool significantly.

The Taguchi-DEAR approach is straightforward and effective. The procedure for evaluating the optimum process parameters in the manufacturing process is known to be extensively accurate. Under the Taguchi-DEAR approach, Muthuramalingam et al. [11] analyzed the process parameters of abrasive flow orientation in AWJM. In the experimental trials where liquid water density, feed rate, AFR, and SoD are the input variables, L9 Taguchi based orthogonal approach has been implemented. Researchers studied improving the MRR and SR characteristics using the Taguchi-DEAR method to solve MCDM problems and determine optimal process parameters. Increasingly, metal matrix composites reinforced with particles combined to form a more complex substance are that to obtain distinguishable physical properties, which also give the high material strength. Making such a material is a tedious task, and consequently, unconventional machining is chosen. Different studies conducted by authors [12] focused on optimizing AWJM factors while processing Al7075 reinforced composites with TiB2 particles. The Taguchi-DEAR technique was used to test MRR, taper angle, and SR from parameters of the water jet pressure input, stand-off distance, and transverse direction. The optimum process parameters are calculated.

\section{EXPERIMENTATION}

\section{Preparation of Al-2Mg Alloy and BFS Composites}

Pure aluminum is melted in a muffle furnace using graphite crucible at $700{ }^{0} \mathrm{C}$, pure magnesium is wrapped in an aluminum foil and dropped in the aluminum melt. The stir casting route was followed for composite preparation. The molten metal pool was stirred at the center of the crucible with the help of a mechanical stirrer, rotating at $600 \mathrm{rpm}$. Blast furnace slag particulates were preheated and dropped uniformly into the melt. To avoid the agglomeration at the time of stirring, the particles were ensured to have a smooth and continuous flow. Since the melt gets exposed to the atmosphere while stirring, argon inert gas-based shielding was maintained throughout for 2 to 3 minutes to avoid oxidation. Then, molten metal is poured into cast-iron molds, which are preheated to $200^{\circ} \mathrm{C}$. The fabricated ingots were kept in an Electric furnace at $110^{\circ} \mathrm{C}$ for 24 hours to remove any residual stresses induced in the castings and reduce the chemical inhomogeneity. 


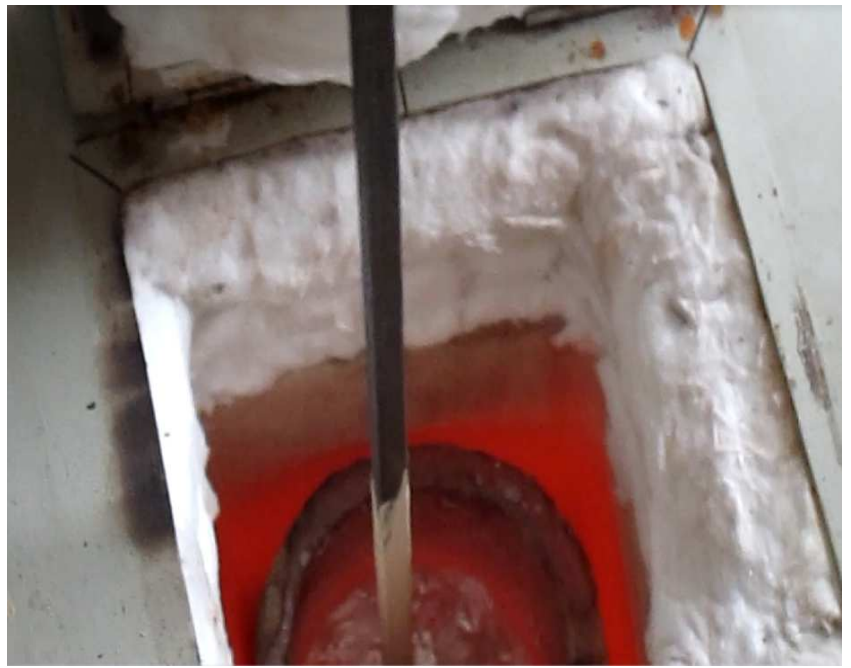

Figure 1: Schematic Diagram Showing the Stir Casting Process.

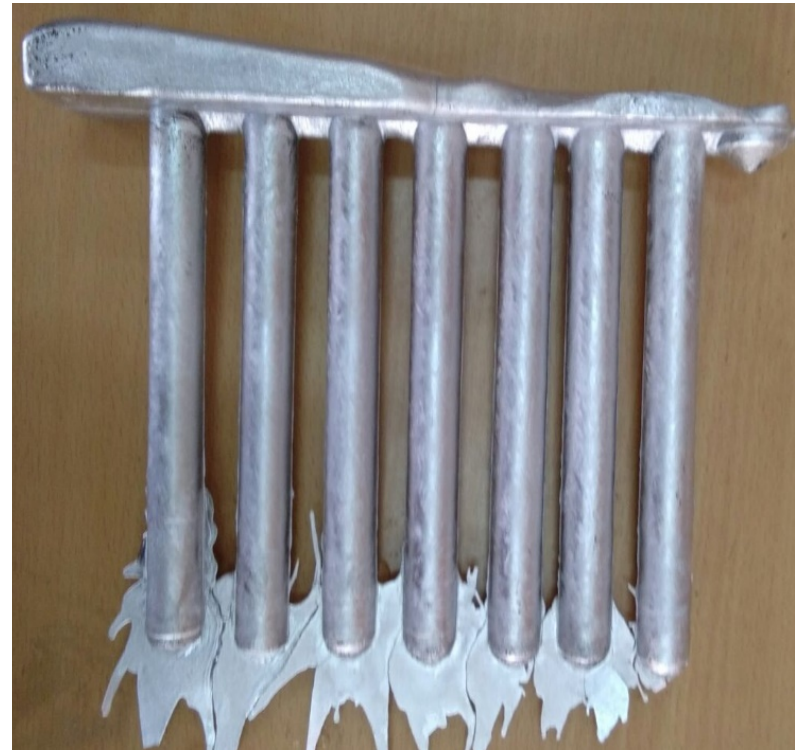

Figure 2: Composite Specimens.

The rough turning on fabricated ingots is first performed on Lathe machine to make specimens of uniform diameter as depicted in figure 2. Initially, based on the available feeds, and speeds on the Lathe, pilot experiments were conducted to find the feed range and speeds for material removal rate as well as excellent surface finish. Once the levels were identified for the depth of cut, cutting speed and feed, the Taguchi's L16 orthogonal array was opted to develop the experimental design. Table 1 lists all the factors and their selected levels.

Table 1: Factors and Levels Selected

\begin{tabular}{|c|l|c|c|c|c|c|}
\hline \multirow{2}{*}{ S. No. } & \multirow{2}{*}{ Factor } & \multirow{2}{*}{ Unit } & \multicolumn{4}{|c|}{ Levels of Factors } \\
\cline { 3 - 7 } & & & $\mathbf{1}$ & $\mathbf{2}$ & $\mathbf{3}$ & $\mathbf{4}$ \\
\hline 1 & Cutting speed, $\mathrm{v}$ & $\mathrm{m} / \mathrm{min}$ & 20 & 50 & 75 & 115 \\
\hline 2 & Feed, f & $\mathrm{mm} / \mathrm{rev}$ & 0.05 & 0.10 & 0.16 & 0.20 \\
\hline 3 & Depth of cut, $\mathrm{d}$ & $\mathrm{mm}$ & 0.2 & 0.4 & 0.6 & 0.8 \\
\hline
\end{tabular}

Mitutoyo's Surf test SJ-210, an instrument which is generally used to measure surface roughness was used in this experiment to calculate the average surface roughness $(\mathrm{Ra})$ of 16 specimens by measuring the surface roughness at three various locations. 


\section{METHODOLOGY}

Multi-objective optimization refers to optimizing the process or product performance that involves two or more outputs simultaneously with or without different outputs. The present work aims to increase the rate of material removal simultaneously while reducing surface roughness. Every inexperienced user can incorporate the proposed offline optimization tools (ENTROPY-GRA and DEAR) to obtain the resulting benefits in industries.

\section{Entropy Weight Method}

The definition of Entropy has been used in the social and physical sciences. A few typical practical applications of Entropy are economics, spectral analysis, and language modeling. Shannon (1948) proposed a theory of mathematical communication. Entropy determines a particular message that is predicted information content. Entropy in the theory of information can be regarded as a criterion for the degree of uncertainty of a discrete distribution of probabilities. The theory of Entropy can be used efficiently in the decision-making process as it tests current comparisons between data sets and clarifies the information transmitted to decision-makers.

The following method should be used to evaluate Shannon entropy (Yoon et al 1981):

Step 1: Normalization of the decision matrix.

$$
K_{l m}=\frac{\gamma_{m}}{\Sigma_{i=1}^{n} \gamma_{m}}
$$

Step 2: Entropy measurement of results calculated using the Eq.(2):

$$
E_{m}=-p \sum_{i=1}^{n} y_{m} \ln y_{l m}
$$

$$
\text { In which } k=1 / \ln (n)
$$

Step 3: defining the weight of the objective based on the entropy concept: the computed weights are presented in table2.

$$
\omega_{m}=\frac{1-E_{m}}{\Sigma_{m=1}^{q}\left(1-E_{m}\right)}
$$

\section{Grey Relational Analysis}

In 1982, Deng introduced the Grey Theory to handle weak, incomplete, and uncertain information. Generally speaking, the system is described with color reflecting the number of specific system details (i.e. internal characteristics or dynamic detailing mathematical formulations). Whether we know the system or process information with absolute detail, it is called a white program. Contrary, if the detail is entirely unknown, it is referred to as the black method. The Grey system refers to the information between the known and the unknown information. The current work is based on optimizing the process of turning and maximizing the MRR thus reducing the SR. The actions taken to improve the use of ENTROPY-GRA are listed below. 

Reinforced Composites using the Taguchi Approach

Table 2: Experimental Values and ENTROPY Weight Method

\begin{tabular}{|c|c|c|c|c|c|c|}
\hline \multirow[t]{2}{*}{ Exp. No. } & \multicolumn{2}{|c|}{ Experimental Values } & \multicolumn{2}{|c|}{ Normalization } & \multicolumn{2}{|c|}{$\mathbf{K}_{\mathrm{Im}}$} \\
\hline & MRR & SR & MRR & SR & MRR & SR \\
\hline E1 & 0.02 & 1.52 & 0.0097 & 0.0506 & -0.0451 & -0.1510 \\
\hline E2 & 0.038 & 1.78 & 0.0185 & 0.0593 & -0.0738 & -0.1675 \\
\hline E3 & 0.066 & 2.48 & 0.0321 & 0.0826 & -0.1105 & -0.2060 \\
\hline $\mathrm{E} 4$ & 0.17 & 2.8 & 0.0828 & 0.0932 & -0.2062 & -0.2212 \\
\hline E5 & 0.042 & 1.72 & 0.0204 & 0.0573 & -0.0795 & -0.1638 \\
\hline E6 & 0.038 & 1.5 & 0.0185 & 0.0500 & -0.0738 & -0.1497 \\
\hline E7 & 0.22 & 2.28 & 0.1071 & 0.0759 & -0.2393 & -0.1957 \\
\hline E8 & 0.174 & 2.32 & 0.0847 & 0.0773 & -0.2091 & -0.1978 \\
\hline E9 & 0.07 & 1.36 & 0.0341 & 0.0453 & -0.1152 & -0.1402 \\
\hline E10 & 0.21 & 1.48 & 0.1022 & 0.0493 & -0.2332 & -0.1484 \\
\hline E11 & 0.112 & 2.14 & 0.0545 & 0.0713 & -0.1586 & -0.1882 \\
\hline E12 & 0.162 & 2.24 & 0.0789 & 0.0746 & -0.2003 & -0.1936 \\
\hline E13 & 0.14 & 1.31 & 0.0682 & 0.0436 & -0.1831 & -0.1366 \\
\hline E14 & 0.22 & 1.39 & 0.1071 & 0.0463 & -0.2393 & -0.1422 \\
\hline E15 & 0.25 & 1.71 & 0.1217 & 0.0569 & -0.2563 & -0.1632 \\
\hline E16 & 0.122 & 2 & 0.0594 & 0.0666 & -0.1677 & -0.1804 \\
\hline SUM & 2.054 & 30.03 & & & -2.5910 & -2.7456 \\
\hline & & & & $\mathrm{E}_{\mathrm{m}}$ & 0.9345 & 0.9902 \\
\hline & & & & $1-E_{m}$ & 0.0655 & 0.0098 \\
\hline & & & & $\mathrm{W}_{\mathrm{m}}$ & 0.87 & 0.13 \\
\hline
\end{tabular}

The normalization process aims to remove the unit variations in the original sequence data and treat the different original sequence data equally. Eq. (4) is used to evaluate the larger-the-better Eq., (5) normalization values when the response data parameters are lower-the-better. In this analysis, surface roughness is a minimum requirement, while MRR is a maximum requirement for productivity enhancement. Table 3 displays the measured normalization values for different responses.

Largerthebetter:

$$
P_{a}^{*}(b)=\frac{P_{a}(b)-\operatorname{Min} P_{a}(b)}{\operatorname{Max} P_{a}(b)-\operatorname{Min} P_{a}(b)}
$$

\section{Smallerthebetter:}

$$
\begin{aligned}
& P_{a}^{*}(b)=\frac{\operatorname{Max} P_{a}(b)-P_{a}(b)}{\operatorname{Max} P_{a}(b)-\operatorname{Min} P_{a}(b)} \\
& P_{a}^{*}(b)=\text { Sequenceafterdataprocessing } \\
& P_{a}(b)=\text { Originalsequence } \\
& \operatorname{Max} P_{a}(b)=\text { Maximumvalueofoutputresponse' } b \\
& \text { Min } P_{a}(b)=\text { Minimumvalue foutputresponse' } b \\
& a=\text { Numberofresponses }(1,2) \\
& b=\text { Numberofexperiments }(1,2 \ldots 16)
\end{aligned}
$$


Step 2: GRC values are calculated for different outputs based on Eq.(6), and results are shown in Table 3. The GRC between the actual and desirable data.

$$
\epsilon_{a}(b)=\frac{\Delta_{\operatorname{Min}}+\zeta \Delta_{M a x}}{\Delta_{0 a}(b)+\zeta \Delta_{M a x}}
$$

Here

$$
\begin{aligned}
& \Delta_{a a}(b)=\left|P_{a}^{o}(b)-P_{a}^{\circ}(b)\right| \\
& \Delta_{\operatorname{Min}}=\operatorname{Min}_{a} \operatorname{Min}{ }_{b} \Delta_{o a}(b) \\
& \Delta_{M a x}=\operatorname{Max}_{a} \operatorname{Max}_{b} \Delta_{o a}(b)
\end{aligned}
$$

Step 3: Calculation of weighted grey relational grade (WGRG) WGRG values can be used to evaluate multiple performance characteristics. This can be determined by taking different responses to the average WGRC values. Eq. (10) used to evaluate the WGRG value and the results were summarized in Table 3

$$
\varphi_{a}(b)=\frac{1}{N} \sum_{i=0}^{N} W_{a} \in_{a}(b)
$$

ENTROPY method supplies the required weights in the present work (see Table 2). Weight fractions for MRR and SR values are found to be 0.87 and 0.13 .

Table 3: Normalized Data, Grey Relational Coefficients and WGRG Values

\begin{tabular}{|c|c|c|c|c|c|c|c|c|}
\hline Exp. No. & \multicolumn{1}{|c|}{ Normalized Data } & $\Delta(\mathbf{M R R})$ & $\Delta(\mathbf{S R})$ & \multicolumn{2}{|c|}{ GRC } & WGRG & S/N Ratio \\
\hline E1 & 0.0000 & 0.8591 & 1.0000 & 0.1409 & 0.3333 & 0.7801 & 0.1957 & -14.1679 \\
\hline E2 & 0.0783 & 0.6846 & 0.9217 & 0.3154 & 0.3517 & 0.6132 & 0.1928 & -14.2962 \\
\hline E3 & 0.2000 & 0.2148 & 0.8000 & 0.7852 & 0.3846 & 0.3890 & 0.1926 & -14.3071 \\
\hline E4 & 0.6522 & 0.0000 & 0.3478 & 1.0000 & 0.5897 & 0.3333 & 0.2782 & -11.1127 \\
\hline E5 & 0.0957 & 0.7248 & 0.9043 & 0.2752 & 0.3560 & 0.6450 & 0.1968 & -14.1194 \\
\hline E6 & 0.0783 & 0.8725 & 0.9217 & 0.1275 & 0.3517 & 0.7968 & 0.2048 & -13.7745 \\
\hline E7 & 0.8696 & 0.3490 & 0.1304 & 0.6510 & 0.7931 & 0.4344 & 0.3732 & -8.5603 \\
\hline E8 & 0.6696 & 0.3221 & 0.3304 & 0.6779 & 0.6021 & 0.4245 & 0.2895 & -10.7669 \\
\hline E9 & 0.2174 & 0.9664 & 0.7826 & 0.0336 & 0.3898 & 0.9371 & 0.2305 & -12.7470 \\
\hline E10 & 0.8261 & 0.8859 & 0.1739 & 0.1141 & 0.7419 & 0.8142 & 0.3757 & -8.5040 \\
\hline E11 & 0.4000 & 0.4430 & 0.6000 & 0.5570 & 0.4545 & 0.4730 & 0.2285 & -12.8233 \\
\hline E12 & 0.6174 & 0.3758 & 0.3826 & 0.6242 & 0.5665 & 0.4448 & 0.2753 & -11.2026 \\
\hline E13 & 0.5217 & 1.0000 & 0.4783 & 0.0000 & 0.5111 & 1.0000 & 0.2873 & -10.8323 \\
\hline E14 & 0.8696 & 0.9463 & 0.1304 & 0.0537 & 0.7931 & 0.9030 & 0.4037 & -7.8789 \\
\hline E15 & 1.0000 & 0.7315 & 0.0000 & 0.2685 & 1.0000 & 0.6507 & 0.4773 & -6.4243 \\
\hline E16 & 0.4435 & 0.5369 & 0.5565 & 0.4631 & 0.4733 & 0.5192 & 0.2396 & -12.4099 \\
\hline
\end{tabular}

\section{Data Envelopment Analysis Based Ranking (DEAR)}

Charnes et al. proposed the 1978 definition of a Data Envelopment Analysis (DEA). The DEA estimates the effectiveness of a mix of decision-making units that produces multiple outputs using multiple inputs. Recall that the DEAR approach used to solve optimization of multiple responses does not allow calculation of weight fractions for individual output characteristics. Here, real output set is compared as a ratio with simple mathematical approximation, so that the calculated values match the ratio ranks. These ranks are therefore used to calculate and optimize the optimal factor level.

The sequential steps for multi-response performance index (MRPI) estimation that was followed in DEAR are: 
Step 1: Determine the weights for each test correspond to all experiments. The calculation is made using the following Eqs. (11) to (15) are used to calculate the weight fraction of each product.

$$
\begin{gathered}
\omega_{M R R}=\frac{M R R}{\sum M R R} \\
\omega_{R_{a}}=\frac{\left(1 / R_{a}\right)}{\Sigma\left(^{1} / R_{a}\right)}
\end{gathered}
$$

Step 2: Transform the output data into weighted data after the output is multiplied with their respective fractions of weight according to Eqs. (11) \& (12).

$$
\begin{aligned}
& M R R=\omega_{M R R} \approx M R R \\
& R_{a}=\omega_{k_{a}} \neq R_{a}
\end{aligned}
$$

Step 3: Calculate the MRPI by using Eq.(14) to distinguish the more significant, the better performance characteristics with the smaller-the-better performance characteristics. MRPI values are shown in Table

$$
M R P I=\frac{M R R}{R_{\Omega}}
$$

Table 4: Weights, MRPI Values

\begin{tabular}{|c|c|c|c|c|c|c|c|c|}
\hline Exp. No. & MRR & SR & \multicolumn{2}{|c|}{ Weights for each output } & M & S & MRPI & S/N Ratio \\
\hline E1 & 0.02 & 1.52 & 0.0097 & 0.0732 & 0.0002 & 0.1112 & 0.0018 & -55.1356 \\
\hline E2 & 0.038 & 1.78 & 0.0185 & 0.0625 & 0.0007 & 0.1112 & 0.0063 & -43.9855 \\
\hline E3 & 0.066 & 2.48 & 0.0321 & 0.0449 & 0.0021 & 0.1112 & 0.0191 & -34.3950 \\
\hline E4 & 0.17 & 2.8 & 0.0828 & 0.0397 & 0.0141 & 0.1112 & 0.1265 & -17.9588 \\
\hline E5 & 0.042 & 1.72 & 0.0204 & 0.0647 & 0.0009 & 0.1112 & 0.0077 & -42.2468 \\
\hline E6 & 0.038 & 1.5 & 0.0185 & 0.0742 & 0.0007 & 0.1112 & 0.0063 & -43.9855 \\
\hline E7 & 0.22 & 2.28 & 0.1071 & 0.0488 & 0.0236 & 0.1112 & 0.2118 & -13.4799 \\
\hline E8 & 0.174 & 2.32 & 0.0847 & 0.0479 & 0.0147 & 0.1112 & 0.1325 & -17.5548 \\
\hline E9 & 0.07 & 1.36 & 0.0341 & 0.0818 & 0.0024 & 0.1112 & 0.0214 & -33.3729 \\
\hline E10 & 0.21 & 1.48 & 0.1022 & 0.0752 & 0.0215 & 0.1112 & 0.1930 & -14.2880 \\
\hline E11 & 0.112 & 2.14 & 0.0545 & 0.0520 & 0.0061 & 0.1112 & 0.0549 & -25.2081 \\
\hline E12 & 0.162 & 2.24 & 0.0789 & 0.0497 & 0.0128 & 0.1112 & 0.1149 & -18.7962 \\
\hline E13 & 0.14 & 1.31 & 0.0682 & 0.0849 & 0.0095 & 0.1112 & 0.0858 & -21.3317 \\
\hline E14 & 0.22 & 1.39 & 0.1071 & 0.0800 & 0.0236 & 0.1112 & 0.2118 & -13.4799 \\
\hline E15 & 0.25 & 1.71 & 0.1217 & 0.0650 & 0.0304 & 0.1112 & 0.2736 & -11.2592 \\
\hline E16 & 0.122 & 2 & 0.0594 & 0.0556 & 0.0072 & 0.1112 & 0.0651 & -23.7224 \\
\hline
\end{tabular}

\section{Determination of Optimal Factor Levels for All Outputs}

Multi-objective optimization methods (ENTROPY-GRA and DEAR) are used to evaluate the sets of optimum factor levels for turning operation. The WGRG and the MRPI values represent the composite values that correspond to all the responses calculated using ENTROPY-GRA (see Table 3) and DEAR (see Table 4). The Taguchi method is now applied to the combined WGRG, and MRPI and the S / N ratio values are calculated. Results have been shown in Tables (5-7) Minitab 18.0 was used to measure the WGRG mean, and MRPI mean for each stage of process parameters and Tables (5-7) listed results. WGRG results were summarized and depicted in Fig 3 for each process parameter. The simple mean of MRPIs (DEAR) respective process parameters were taken as Taguchi predicted optimum process parameter settings. The optimum 
settings were predicted by Taguchi as $\mathrm{v}=115 \mathrm{~m} / \mathrm{min}, \mathrm{f}=0.2 \mathrm{~mm} / \mathrm{rev}$ and $\mathrm{d}=0.8 \mathrm{~mm}$ ( $\mathrm{v} 4-\mathrm{f} 4-\mathrm{d} 4)$ respectively shown in Fig.5.

Table 5: Response Table of S/N Ratio for WGRG

\begin{tabular}{|c|c|c|c|}
\hline Level & $\mathbf{v}$ & $\mathbf{f}$ & $\mathbf{d}$ \\
\hline 1 & -13.471 & -12.967 & -13.294 \\
\hline 2 & -11.805 & -11.113 & -11.511 \\
\hline 3 & -11.319 & -10.529 & -11.425 \\
\hline 4 & -9.386 & -11.373 & -9.752 \\
\hline Delta & 4.085 & 2.438 & 3.542 \\
\hline Rank & 1 & 3 & 2 \\
\hline
\end{tabular}

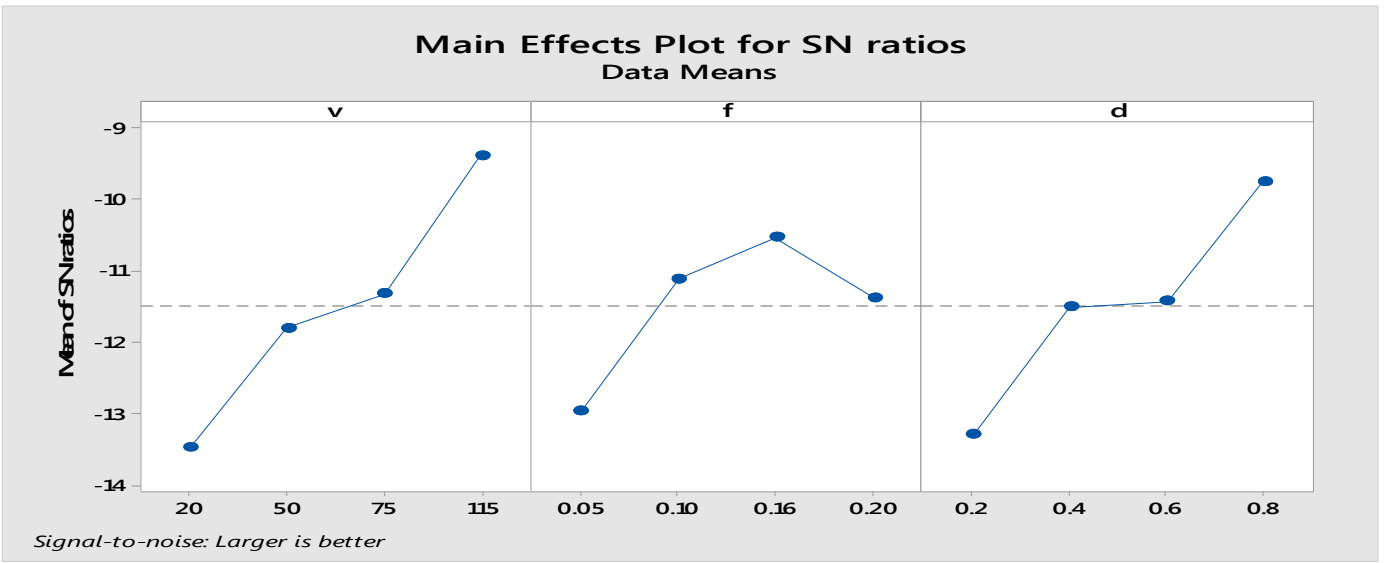

Figure 3: Means of S/N Ratios of WGRG.

Table 6: Response Table of S/N Ratio for MRPI

\begin{tabular}{|c|c|c|c|}
\hline Level & $\mathbf{v}$ & $\mathbf{f}$ & $\mathbf{d}$ \\
\hline 1 & -37.87 & -38.02 & -37.01 \\
\hline 2 & -29.32 & -28.93 & -29.07 \\
\hline 3 & -22.92 & -21.09 & -24.7 \\
\hline 4 & -17.45 & -19.51 & -16.76 \\
\hline Delta & 20.42 & 18.51 & 20.25 \\
\hline Rank & 1 & 3 & 2 \\
\hline
\end{tabular}

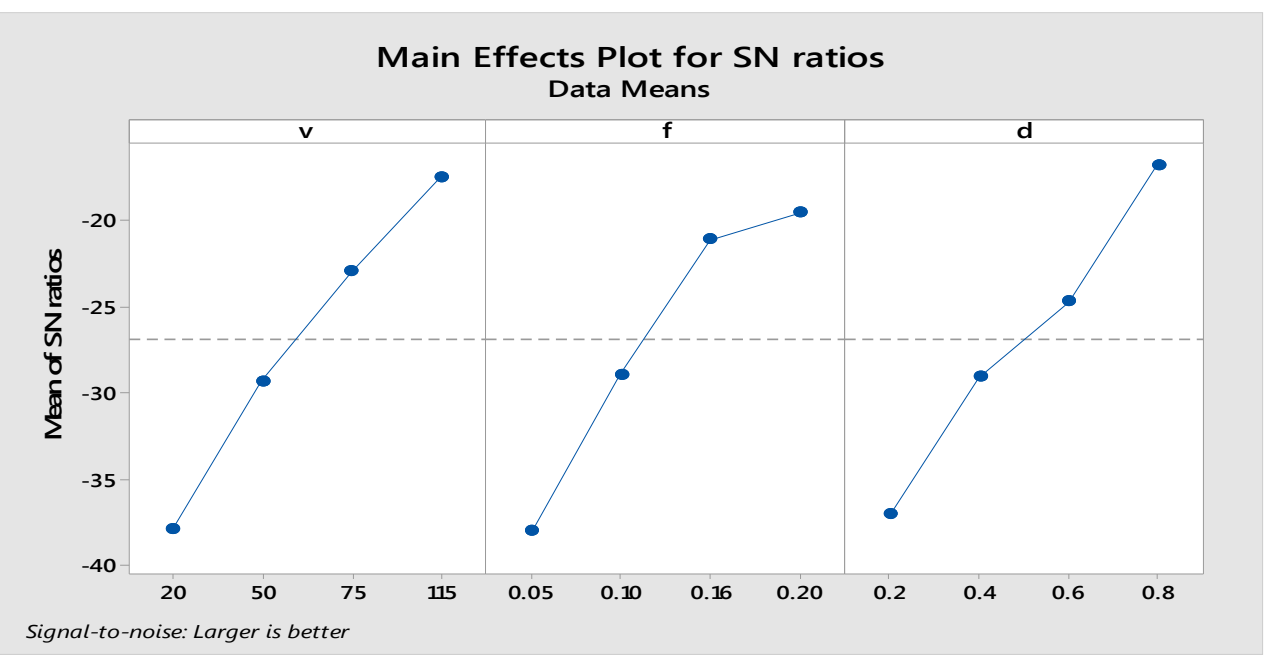

Figure 4: Means of S/N Ratios of MRPI. 


\section{Confirmation Experiments}

Confirmation tests are performed to validate the predictions of optimal techniques and to select the best method of optimization to improve the Turning process's multiple output features. Note that the DEAR method outperformed compared with ENTROPY-GRA to determine the optimum levels resulting in desired high MRR values and low SR values. Remember that the DEAR approach provided an increase of 39.1\% in MRR, 2.32\% in SR, respectively (see Table 11), $\mathrm{v}_{4} \mathrm{f}_{4} \mathrm{~d}_{4}$, therefore, corresponds to the optimal set of factor levels suggested for the Turning process by the DEAR test. The importance of individual factors was evaluated based on the rank of the factors in response tables (Table5-6). Cutting speed followed by feed and depth of cut are factors that are identified according to their importance in enhancing multiple performance characteristics.

Table 7: Comparison of Confirmation Test Results

\begin{tabular}{|c|c|c|c|c|c|}
\hline $\begin{array}{c}\text { Process } \\
\text { parameter }\end{array}$ & $\begin{array}{c}\text { Initial machining } \\
\text { parameter settings }\end{array}$ & \multicolumn{2}{c|}{ Optimal process } & \multicolumn{2}{c|}{ Percentage change in results } \\
\hline & & ENTROPY-GRA & DEAR & ENTROPY-GRA & DEAR \\
\hline & $\mathrm{v}_{3}-\mathrm{f}_{3}-\mathrm{d}_{3}$ & $\mathrm{v}_{4}-\mathrm{f}_{3}-\mathrm{d}_{4}$ & $\mathrm{v}_{4}-\mathrm{f}_{4}-\mathrm{d}_{4}$ & & \\
\hline SR & 1.72 & 1.72 & 1.68 & $0 \%$ improvement & $2.32 \%$ improvement \\
\hline MRR & 0.23 & 0.28 & 0.32 & $21.7 \%$ improvement & $39.1 \%$ improvement \\
\hline
\end{tabular}

\section{CONCLUSIONS}

Through experimental study, conclusions were drawn.

- Numerous outputs produce various solutions and depend on the complexity of the response's value. Traditional practices (engineers or experts or customer advice) may deliver the best output for one output, with the other being compromising solutions. The weight fractions based on the data collected from the output were evaluated bt ENTROPY methods. The weight fractions calculated by the ENTROPY method for MRR and SR are 0.87 and 0.13 , respectively. Remember that the summation of all weights must be held equal to one output.

- For multi-objective optimization, GRA allows weight fractions to be allocated. Therefore, the ENTROPY method supplies the weights ready to solve the problem. Note that for optimization, ENTROPY-GRA uses various procedural steps.

- The optimal combination of cutting conditions as $\mathrm{v}=115 \mathrm{~m} / \mathrm{min}, \mathrm{f}=0.16 \mathrm{~mm} / \mathrm{rev}$ and $\mathrm{d}=0.8 \mathrm{~mm}\left(\mathrm{v}_{4}-\mathrm{f}_{3}-\mathrm{d}_{4}\right) \mathrm{were}$ determined from ENTROPY-GRA.

- The optimum turning parameters were observed at $\mathrm{v}=115 \mathrm{~m} / \mathrm{min}, \mathrm{f}=0.2 \mathrm{~mm} / \mathrm{rev}$ and $\mathrm{d}=0.8 \mathrm{~mm}\left(\mathrm{v}_{4}-\mathrm{f}_{4}-\mathrm{d}_{4}\right)$, respectively, using the DEAR multi-objective optimization method.

- In their experimental trials, DEAR methodological measures estimate the weight fractions for each output. The suggested optimal levels $\left(\mathrm{v}_{4}-\mathrm{f}_{4}-\mathrm{d}_{4}\right)$ and importance-based ranking of factors are, therefore, different from those obtained from ENTROPY-GRA.

- For the optimal levels suggested by all two methods, the confirmation experiments are conducted. DEAR method outperformed the model (ENTROPY-GRA) to produce higher material removal rates with low surface roughness. Notice that DEAR and method provided an increase of 39.1 percent in MRR and 2.32 percent in SR over other (i.e., ENTROPY-GRA) model. This happens because each model has its advantages and limitations with an 
acceptable degree of error in value estimation. Also, the ENTROPY-GRA model increases the complexity and time consuming of the computation. Consequently, the DEAR approach is an appropriate tool that increases the quality of the product and offers solutions without the complexity and time of computation. This could encourage any professional or inexperienced engineer to apply practical problem-solving methods.

\section{REFERENCES}

1. Mishra, P. C. (2015). Tool wear in turning ceramic reinforced aluminum matrix composites-A review. Journal of Composite Materials, 49(24), 2949-2961.

2. Rao, K. P. (2008). Machinability issues in turning of Al-SiC (10p) metal matrix composites. The International Journal of Advanced Manufacturing Technology, 39(3-4), 211-218.

3. Balazinski, M. (2018). Turning titanium metal grid composites (Ti-MMCs) with carbide and CBN embeds. The International Journal of Advanced Manufacturing Technology, 97(1-4), 253-265.

4. Saxena, Swati, and Madhavi Sinha. "Single-response metric analysis of adaptive fault tolerant replication routing protocol for manets using taguchi approach." International Journal of Computer Networking, Wireless and Mobile Communications (IJCNWMC) 3.3 (2013): 105-116.

5. Dandekar, C. R., \& Shin, Y. C. (2012). Modeling of machining of composite materials: A review. International Journal of Machine tools and manufacture, 57, 102-121.

6. Ramamoorthy, B., \& Vijayaraghavan, L. (2009). Optimization of high speed turning parameters of superalloy Inconel 718 material using the Taguchi technique.

7. Yang, W. P., \& Tarng, Y. S. (1998). Design optimization of cutting parameters for turning operations based on the Taguchi method. Journal of materials processing technology, 84(1-3), 122-129.

8. Kumar, Labesh, T. Vanaja, and M. Mahender Reddy."“Optimization of Parametres for Weldability Strength-An Experimental Design Approach." International Journal of Mechanical and Production Engineering Research and Development (IJMPERD), $\operatorname{ISSN}(P)$ (2018): 2249-6890.

9. Zuperl, U., Cus, F., \& Milfelner, M. (2005). Fuzzy control strategy for adaptive force control in end-milling. Journal of Materials Processing Technology, 164, 1472-1478.

10. KKadirgama., Noor, M. M., \& Rahman, M. M. (2012). Optimization of surface roughness in end milling using potential support vector machine. Arabian Journal for Science and Engineering, 37(8), 2269-2275.

11. Srikanth, D. V., and M. Sreenivasa Rao."Application of optimization methods on abrasive jet machining of ceramics." International Journal of Industrial Engineering \& Technology (IJIET) 4.3 (2014): 23-32.

12. L.F.Mondolfo. Aluminum alloys-Structure and properties. 1976; p.18-19.

13. Lin, C. L. (2004). Utilization of the Taguchi technique and dim social investigation to upgrade turning activities with various execution attributes. Materials and assembling forms, 19(2), 209-220.

14. Kumar, M. Naveen, Sriram. Venkatesh, and M. Manzoor Hussain."Experimental investigation on influence of process parameters in selective laser sintering on roundness using taguchi medthod." International Journal of Mechanical and Production Engineering Research and Development 7.6 (2017): 45-52. 
15. Muthuramalingam T, Vasanth S, Vinothkumar P, Geethapriyam T, Rabik MM (2018) Multi-criteria decision making of abrasive flow-oriented process parameters in abrasive water jet machining using Taguchi-DEAR methodology. Springer Science + Business Media B.V., part of Springer Nature

16. Manoj M, Jinu GR, Muthuramalingam T (2018) Multi response optimization of AWJM process parameters on machining TiB2 particles reinforced Al7075 composite using Taguchi-DEAR methodology. Springer Science + Business Media B.V., part of Springer Nature 

